DOI: $10.17805 /$ ggz.2019.2.3

\title{
Репрезентация русской классики в западном мире: британская интерпретация «Евгения Онегина»
}

Е. Н. Шапинская

Российский государственный университет физической культуры, спорта, молодежси и туризма, г. Москва

Статья написана на основе доклада на III Академических чтениях памяти Вл. А. Лукова «Тезаурусы и проблемы культурыл», прошедшей в Московском гуманитарном университете 4 апреля 2019 г. Изучение взгляда на русскую культуру как на Другого важно как для самоидентификации культуры, так и для понимания ее универсальных, вечных сюжетов и образов. На примере интерпретации «Евгения Онегина» как литературного и музыкального текста проанализированы репрезентационные стратегии в отношении культуры Другого с точки зрения их важности для понимания культурной идентичности.

Ключевые слова: репрезентация; самоидентификаиия; Другой; интерпретаиия; культурный текст; стереотип; постсовременность; тезаурусный подход; бинарные оппозиции; «Евгений Онегин»; А. С. Пушкин

\section{Representation of Russian Classics in the Western World: British Interpretation of "Eugene Onegin"}

\author{
E. N. Shapinskaya
}

Russian State University of Physical Education, Sport, Youth and Tourism, Moscow

The article draws on the paper presented at the 3rd Academic Readings in the Memory of Vladimir A. Lukov "Thesauri and Issues of Culture" (Moscow University for the Humanities, April 4, 2019). An examination of the attitude to Russian culture as the Other is significant both for self-identification of culture and for understanding its universal, eternal plots and images. Using the case of "Eugene Onegin" as a literary and musical text, the author analyzes representative strategies in relation to the culture of the Other in the context of their importance for insight into cultural identity.

Keywords: representation; self-identification; Other; interpretation; cultural text; stereotype; postmodernity; thesaurus approach; binary oppositions; "Eugene Onegin"; A. S. Pushkin 


\section{ВВЕДЕНИЕ}

Формирование представлений о русской культуре за пределами России происходит, в основном, на основе репрезентаций в различных культурных текстах и художественных формах. Еще Т. Адорно, подвергший всесторонней критике «культурную индустрию», отмечал власть репрезентаций и их способность затмевать реальность. По его мнению, культурная индустрия претендует на упорядочивающую роль в хаотическом мире, хотя, по сути дела, она этот мир разрушает: «Цветной фильм разрушает уютную старую таверну быстрее, чем это могли бы сделать бомбы. Фильм уничтожает ее образ. Никакое родное место не может пережить обработку фильмом, который прославляет его и, таким образом, превращает его уникальный характер, основу его жизненной силы в неизменную одинаковость» (Adorno, 1990: 279; пер. наш. - E. $W$.). Погруженный в мир репрезентаций человек часто не готов воспринимать реальность, которая может казаться менее яркой и выразительной, чем созданные при помощи технических средств образы. В то же время отношение к миру часто бывает сформированным еще до того, как человек сталкивается с его различными сторонами, и власть репрезентации может быть настолько сильной, что способна полностью затмить видение реальности. Это в полной мере относится к формированию отношения к культуре Другого и ее представителям.

В тезаурусном подходе изучению роли Другого, чужака отводится важное место: «Осмысление идентичности как существенного фактора индивидуальной и коллективной жизни в современных научных теориях начинается с осмысления социальной роли чужака Георгом Зиммелем» (Луков В., Луков Вл., 2008: 20).

Политика репрезентации Другого может быть нацелена как на поддержание обыденных представлений, так и на их изменение, «рассеивание мифа». Переходный период рубежа тысячелетий характеризуется значительными сдвигами в отношении к Другому - приравнивание Другого к Врагу, весьма распространенное в определенных обществах на протяжении долгого времени, в постмодернистской культурной ситуации уступает место принципам культурного плюрализма, что неизбежно ведет и к пересмотру собственной идентичности. В то же время массовая культура продолжает воспроизводить в популярных формах стереотипы, ей же созданные и приносящие немалый доход, отсюда устойчивость представлений о Другом как о враждебном или варварском оппоненте демократическим ценностям западной цивилизации. 
СТЕРЕОТИПЫ «РУССКОСТИ» В «ПОСТКУЛЬТУРЕ»

В области репрезентации русской культуры как культуры Другого соседствуют стереотипы, основанные на традиционных бинарных оппозициях типа «Россия / Запад», с одной стороны, и новые формы репрезентации, осуществляемые в рамках интенсивной глобализации и межкультурной коммуникации, с другой. Поскольку грань между популярной и «высокой» культурой в плюралистическом обществе сегодняшнего дня весьма зыбкая, то и тексты, получившие статус русской классики, чаще всего становятся объектом «упрощенных» экранных репрезентаций, входят в поле медиакультуры, которая является средой формирования представлений и вкусов (пост)современного человека. В то же время, как мы это покажем ниже, западная культура проявляет серьезный интерес к глубинным смыслам русских классических произведений, их общечеловеческому звучанию, эмоциональному миру героев. Обе эти тенденции важны для позиционирования своей культуры в современном культурном пространстве, для установления продуктивного межкультурного диалога, основанного на признании правомочности взгляда на Себя как Другого и, в конечном итоге, вхождении в пространство интерсубъективности, в котором возможно сосуществование различных культур как равных в ценностном отношении.

Время, в которое мы живем, характеризуется пересмотром многих понятий, деконструкцией традиционных бинарных оппозиций, появлением на культурной сцене новых групп, которые были исключены из доминантной культуры или становились маргинальными, демифологизацией старых героев и в то же время расцветом новой мифологии, избыточностью и легкой доступностью информации. Недаром культурное состояние рубежа тысячелетий часто называется «посткультурой». Проблема Другого обретает в «посткультуре» новое звучание, Другой обретает голос, получает право на утверждение собственной идентичности, что ведет и к пересмотру распространенного отношения к Другому как к врагу. Причины этого отношения связаны с проблемами самоидентификации человека в сложном мире культурного плюрализма. Образ Другого как врага весьма распространен в текстах популярной культуры, где он конструируется в гипертрофированном виде, с преувеличением черт враждебной «другости» в соответствии с господствующими в обществе идеологическими установками. По мере того как в отношении к тому или иному типу Другого враждебность сменяется пониманием, толерантностью или установлением диалога, возникают новые устрашающие образы, показывающие, что человек нуждается во враждебном Другом, чтобы ощутить в себе силу борьбы с тем, что представляет угрозу стабильности его существования. Достаточно вспомнить образы русских злодеев из бондианы Яна Флеминга, актуальных во времена холодной войны, которые потеряли 
свой пафос в постсоветский период и были заменены образами террористов нового типа, угрожающих западной демократии.

Необходимость человека в Другом, как на уровне индивида, так и группы, настолько велика, что «другость» продолжает оставаться одной из ведущих составляющих социокультурной реальности и области репрезентаций. Известный социолог XX века 3. Бауман отмечает эту связь Другого с человеческим существованием, отмечая, что самое главное различие в человеческом обществе проявляется сильнее и больше влияет на отношения с другими, чем все остальные, это - различие между «Мы» и «Они». Бауман излагает традиционную позицию отторжения по отношению к Другому и подчеркивает, что она основана на незнании и непонимании. Соответственно, в эпоху расширения коммуникаций до всемирного масштаба, воплощенного в сети Интернет, казалось бы, незнание должно быть преодолено. Тем не менее, это преодоление идет медленно и встречает сопротивление со стороны культурной индустрии, получающей прибыль из популярных форм репрезентации расхожих стереотипов. С одной стороны, многие этнокультурные стереотипы не выдерживают расширения знания о других культурах и широкого распространения информации о художественных практиках Другого. С другой стереотипы продолжают проявлять необыкновенную устойчивость даже перед лицом опровергающей их реальности и формируют представления о «русскости» в массовом сознании. Это происходит не только в случае с голливудскими боевиками, где герой попадает в мифологическую Россию со всеми ее атрибутами в виде матрешек, медведей и водки, но и в различных интерпретациях русской классики.

Оговоримся сразу, что мы имеем в виду масскультовские образцы. Можно привести в качестве примера многочисленные (всего около 30) экранизации романа Л. Н. Толстого «Анна Каренина», в которых приметы «русскости» с разной степенью экзотичности показываются в рамках давно устаревших стереотипов. Такая политика репрезентации несомненно рассчитана на коммерческий успех у малоподготовленного зрителя. Тем не менее, как отмечает известный исследователь культуры постмодернизма Ф. Джеймсон, «эта привлекательность этничности идет сегодня на убыль, может, потому что существует слишком много групп населения и потому что их связь с репрезентацией (по большей части медийной) становится все яснее и подрывает онтологические основы фикциональности» (Jameson, 1995: 342; пер. наш. - E. W.).

Если в популярной культуре конструкция образа «русскости» основана на стереотипах массового сознания и потреблении «экзотики», в культурных формах, основанных на классических текстах и претендующих на серьезное осмысление наследия Другого (в данном случае русской классики), акцент 
делается не столько на внешнюю экзотичность, сколько на понимание «русской души» и на выявление универсальных смыслов, делающих то или иное произведение явлением, выходящим за рамки локальной культуры, содержащим вечные темы и образы.

Характеристики вечных образов позволяют обращаться к ним в любых историко-культурных контекстах, включать их в различные формы интерпретации. Среди свойств таких образов авторы тезаурусного подхода выделяют следующие: «содержательная емкость, неисчерпаемость смыслов; высокая художественная, духовая ценность; способность преодолевать границы эпох и национальных культур, общепонятность, непреходящая актуальность... переводимость на языки других искусств, а также языки философии, науки и т. д.» (Луков В., Луков Вл., 2008: 116). Можно привести много примеров из области кино, драматического и музыкального театра, обращавшихся и обращающихся сегодня к вечным образам русской классики. Осознавая великий вклад русской культуры в мировой культурный ресурс, западные деятели культуры пытаются создать собственные интерпретации, основанные не на внешних деталях, а на проникновении во внутренний мир автора и его героев. Для понимания созданных на Западе художественных текстов такого рода, мы обратимся к А. С. Пушкину, который редко попадает в пространство интерпретации на Западе, несмотря на его статус в русской литературе и культуре в целом.

\section{«ЕВГЕНИЙ ОНЕГИН» НА ЭКРАНЕ И НА ОПЕРНОЙ СЦЕНЕ}

Несмотря на признание А. С. Пушкина как великого классика русской литературы и культуры в целом, его произведения плохо поддаются переводу на иностранные языки, в основном, несомненно, по причине сложности передачи поэтической формы одного языка на другом. В то же время поэт стал богатейшим источником создания культурных текстов в области музыки и кинематографа, поскольку как поэзия, так и проза обладают способностью создавать новые формы с использованием выразительных средств других языков культуры. Именно тексты Пушкина легли в основу величайших опер П. И. Чайковского — «Евгения Онегина» и «Пиковой дамы», романсового творчества М. И. Глинки, а кинорежиссеры перенесли на экран практически всю прозу Пушкина. Тем не менее, для западного мира Пушкин в большей степени Другой, чем более известные авторы-прозаики, такие как Ф. М. Достоевский или А. П. Чехов. Насколько поэзия поддается переводу на иностранные языки как литературная форма, насколько можно передать содержание поэтического произведения, неразрывно связанное со стихотворной формой, поэтическим языком с его специфической звуковой и семантической 
системой - вопрос сложный. В нашем случае интерес представляет фокус внимания интерпретатора, баланс между «русскостью» и общечеловеческими эмоциями и ценностями, способы его достижения в различных видах репрезентации. Выбор такого произведения как «Евгений Онегин» представляет очень сложную задачу для зарубежного интерпретатора, прежде всего, по причине поэтического характера текста, который стал хрестоматийным для поколений русских школьников и давным-давно разошелся на цитаты в русском обществе.

Мы рассмотрим те пространства репрезентации, в которых «Евгений Онегин» стал объектом интерпретации английскими режиссерами и исполнителями - кинематограф и оперу. Каждое из этих культурных пространств обладает своим собственным языком, в большей или меньшей степени позволяющим передавать смысл литературного текста-первоосновы.

Вначале обратимся к фильму «Онегин» (реж. Марта Файнз, 1999). Задача создателей фильма была трудна во многих отношениях — им предстояло «перевести» литературное произведение на экранный язык, а, кроме того, донести до зрителя переведенный текст иноязычного автора, т. е. осуществить двойную трансляцию. Проблема «перевода» одного языка культуры на другой, в частности, возможность «рассказать» литературное произведение языком экрана, является весьма важной в современной теории культуры. Отечественный исследователь современной культуры Н. А. Хренов отмечает, что в своих ранних формах литература была также скорее зрелищна, чем нарративна, и считает зрелищность начальной формой литературного развития. Кинематограф, с его точки зрения, лучше всего соответствует именно этим ранним литературным формам, что делает их сопоставление вполне возможным. Соглашаясь с тем, что литературные тексты могут быть «зрелищными», мы все же обращаем внимание на противоположное явление - на то, что экранные тексты могут быть нарративными. Это означает, прежде всего, расстановку акцентов в репрезентации - то, как то или иное событие или персонаж показан, или то, как о нем рассказано. В предпринятом нами исследовании «другости» в кино именно нарративный кинотекст играет наиболее важную роль. Во-первых, как мы уже указывали, он преобладает в популярной культуре, наиболее обширном культурном пространстве, где складываются представления о Другом. Кроме того, через нарратив представление о Другом раскрывается постепенно, формируя цельную картину, а не отрывочные впечатления. Нарративные тексты формируют весьма устойчивые представления, воплощая художественные архетипы. В то же время кинематографический нарратив усилен визуальными средствами. Если мы имеем дело с высоким уровнем профессионализма и ответственности, можно говорить о том, что визуальный образ помогает в формировании у зрителя образа, соответствующего 
реальности. Оставив в стороне многочисленные фильмы про «русских», основанные на востребованной публикой ложной экзотике, мы видим, что визуальные образы помогают сформировать представления о литературных персонажах, особенно в том случае (как это преимущественно и случается в наши дни), когда знакомство с экранным текстом предшествует чтению книги. Тема Другого, согласно Ж. Делезу, является очень важной и для кино, во всяком случае звукового. Отношения с Другим могут быть поверхностными и преходящими именно внешне, поскольку их конфигурации зависят от самых разных обстоятельств, в том числе и от субъектной позиции автора и зрителя, которая имеет тенденцию становиться более подвижной. Но на более глубоком уровне обращение к Другому связано с сущностной потребностью в нем, которую сам же Делез и отмечает, цитируя формулу А. Рембо «Я — это другой».

Фильм «Онегин» является, несомненно, кинематографическим нарративом - авторы сознательно отказываются от поэтической составляющей, рассматривая пушкинский роман в стихах (а именно так определен жанр произведения самим автором) как рассказ о жизненных судьбах героев, помещенный в контекст некоего довольно условного пространства «русскости», что особенно ощущается в музыкальных «несуразностях». Так, в фильме звучит вальс «На сопках Маньчжурии», написанный в 1906 г., Ольга с Ленским поют дуэтом песню «Ой, цветет калина в поле у ручья», написанную в 1950 г. И. О. Дунаевским для фильма «Кубанские казаки». Тем не менее, фильм стал рассказом о человеческих чувствах и характерах, которые существовали и существуют вне зависимости от архитектурного или музыкального оформления. Вкрапления поэтического текста в прозаический нарратив подчеркивают эмоциональную важность любовных чувств, заставляющих даже самого обычного человека на время становиться поэтом. Как отметил кинокритик С. В. Кудрявцев, «зарубежные авторы ленты “Онегин” (чуть отличающееся название будто дает им определенную надежду на прощение) рискнули сделать то, на что не решился бы никто из отечественных экранизаторов, доведись кому из них набраться наглости и воплотить в кино роман в стихах “Евгений Онегин”. Они вообще отказались от стихотворного текста, не считая писем Татьяны и Евгения. И то девичье признание в любви, наизусть заученное нами еще в школе, не без оригинальности озвучивается вслух гораздо позже, когда спустя шесть лет Онегин, вновь встретив Ларину и влюбившись в нее, перечитывает старое письмо, прежде чем написать ей о своих новых чувствах. Если принять эти правила игры и не быть литературоведчески придирчивыми, то такое обращение с бессмертным пушкинским текстом действительно заслуживает снисхождения. Как и ряд иных вольностей, необходимых для того, чтобы по возможности насытить диалог героев живыми по- 
дробностями, позаимствованными из поэтических отступлений» (Кудрявцев, 2006: Электронный ресурс). Позиция, выраженная в данном отзыве, весьма распространена среди «этноцентристов», которые считают, что понять и представить культуру могут только ее носители. Возникает вопрос - нужно ли рассматривать обращение к культурным текстам Другого достойным лишь снисхождения? Не является ли взгляд на себя «со стороны» весьма полезным для самоидентификации в глобальном культурном пространстве? К тому же, существует немало примеров блестящей интерпретации мировой классики представителями другой культуры, достаточно вспомнить «Гамлета» Г. М. Козинцева или образ Шерлока Холмса в великолепном исполнении В. Б. Ливанова.

Авторы фильма «Онегин» сознательно придерживаются концепции В. В. Набокова, а также его прозаического перевода пушкинской поэмы. Как известно, писатель считал невозможным передать художественную сторону поэмы, а единственной задачей переводчика считал наиболее точную передачу информации и однозначно отвечал «нет» на вопрос о возможности передачи рифмованных стихов на иностранном языке: «Перед нами вовсе не “картина русской жизни", - писал Набоков о “Евгении Онегине", — в лучшем случае, это картина, изображающая небольшую группу русских людей, живущих во втором десятилетии XIX в., имеющих черты сходства с более очевидными персонажами западноевропейских романов и помещенных в стилизованную Россию...» (Набоков, 1998: 36). Не делая акцента на «русскости» персонажей и сценографии, М. Файнз идет вслед за В. В. Набоковым, своим прозаическим переводом подчеркивавшим общеевропейский характер пушкинского шедевра.

Хотя нарративная ткань пушкинского «Онегина» вплетает в себя разнообразный круг действующих лиц, все же главное в нем - судьба героя, который закономерно становится центром экранной интерпретации Рэйфа Файнза, замечательного, тонкого актера, для которого обращение к русской классике далеко не случайно. Британский актер снялся в фильме В. В. Глаголевой «Две женщины» по пьесе «Месяц в деревне» Тургенева, играл на сцене во многих пьесах А. П. Чехова. Это еще раз подтверждает нашу идею по поводу преодоления «другости» в современных интерпретациях классики. Именно вокруг печальной судьбы главного героя плетется ткань нарратива. Если Татьяна - олицетворение юности, непосредственности, эмоциональности, которые не способна уничтожить до конца даже холодность громадного аристократического дома, в котором она после замужества ведет жизнь светской дамы, то Онегин воплощает в себе вечную проблему человека, не нашедшего смысл жизни. Трудно представить себе «посткультурную» интерпретацию классического образа без постмодернистской иронии, что и отмечали крити- 
ки фильма, который, надо сказать, был весьма неоднозначно воспринят как профессионалами-киноведами, так и публикой: «Рейф Файнз в роли Евгения Онегина настолько мрачно романтичен и цинично холоден, что временами это начинает производить почти комический, пародийный эффект. Остраняемая поэтом и не без иронии поданная чайлд-гарольдская внешность героя понята актером словно всерьез, и несколько его естественных реакций не могут изменить складывающееся превратное впечатление об Онегине как о скучающем мизантропе, который готов всех презирать...» (Кудрявцев, 2006: Электронный ресурс). С одной стороны, этот образ соответствует чертам «байронического героя»: «Раннее пресыщение жизнью. Утрата связи с окружающим миром. Страшное чувство одиночества. Эгоцентризм... Таким образом, свободный от общества герой несчастен, но независимость для него дороже покоя, уюта, даже счастья» (Луков В., Луков Вл., 2008: 323-324). Подчеркнуто мрачный образ Онегина может, несомненно, рассматриваться в контексте всего постмодернистского культурного производства, в котором осознается, что все культурные формы репрезентации - литературные, визуальные, акустические - в высоком искусстве или в массмедиа, являются идеологически обоснованными, что они не могут избежать вовлеченности в социальные и политические отношения. С этой точки зрения помещение героя поэмы Пушкина в некий условный общеевропейский контекст вполне соответствует процессам глобализации, быстро нивелирующим этнокультурные различия.

С другой стороны, Онегин - вечный Другой, не зависящий от этнокультурных примет «другости», он - персонаж универсальный, «человек мира», в том понимании мира, которое существовало в европейском дискурсе в предшествующую деколонизации эпоху, поэтому приметы «русскости»в его интерпретации становятся лишними. Он принадлежит миру, и в то же время, он - вечный Другой в этом мире.

Иной пример обращения британских деятелей искусства к пушкинскому роману в стихах лежит в области музыки - это постановка оперы П. И. Чайковского «Евгений Онегин» в лондонском театре «Ковент-Гарден» (реж. Каспер Холтен, 2013). Мы обращаемся к этой постановке, а не к тем спектаклям западных театров, где заняты в основном русские исполнители, поскольку она наиболее отчетливо представляет взгляд Другого. Постановка эта симптоматична с точки зрения общего интереса к русской музыкальной классике на Западе, причем в опере реализация этого интереса гораздо сложнее, чем в других музыкальных формах, поскольку предполагается исполнение на русском языке. При перенесении любого культурного текста в инокультурную среду всегда возникают проблемы трансляции смыслов, соответствия терминов, трансформации культурного кода. В случае оперы, сочетающей в себе музыкальный и вербальный элементы, эта задача весьма сложна и 
требует понимания как первоисточника, так и контекста репрезентации. По мнению Д. Ю. Густяковой, «происходит режиссерский “перевод” классического текста на язык “Другого”, текст адаптируется к восприятию инокультурной публикой. Зачастую режиссеры, следуя путем отказа от историкокультурной специфики классического оперного текста, ведут русскую оперу в направлении глобализационных процессов, унифицируя художественный образ, упрощая его до сюжетной формулы, типологической модели» (Густякова, 2015: 138).

В лингвистическом отношении «другость» русской культуры преодолевается с бо́льшим трудом, чем в случае других, более привычных языков исполнения. Так, «в постановке “Евгения Онегина" театра “Ковент-Гарден” заняты певцы из разных стран (болгарка Крассимира Стоянова - Татьяна, россиянка Елена Максимова — Ольга, словак Павол Бреслик - Ленский и другие). Оказывается, петь на русском - не так легко, как нам может казаться, особенно для певцов, не владеющих славянскими языками. И если Крассимира Стоянова поет с едва уловимым акцентом, то британский бас Петер Роуз (князь Гремин) звучит приблизительно так: “Оньегин, я скрывать не стану, бьезумно я люблю Татьяну. Тоскливо жизнь моя тьекла, она явилась и зажгля...”» (Мельниченко, 2013: Электронный ресурс). Эта лингвистическая «другость» ощущается, несомненно, только носителями языка и присутствует в любом виде межкультурной коммуникации, не только художественной. Для англоязычной критики более важна фразировка и свобода произношения, хотя в данном случае работа по освоению русского текста была проделана самая серьезная. Исполнитель роли Онегина известный английский баритон Саймон Кинлисайд, за плечами которого не одна постановка «Онегина» в европейских театрах, настолько хорошо «использовал язык, что каждая строчка была спроецирована и, хотя он не говорит свободно по-русски... казалось, что он чувствует себя в этом языке абсолютно свободно» (Operatraveller, 2013: Электронный ресурс). Как режиссер, так и исполнитель говорят о том, что только в слитности языка и музыки проявляется вся красота произведения Пушкина и Чайковского. Несмотря на все трудности исполнения на незнакомом языке и необходимость понимания каждого слова, только такое исполнение дает зрителю / слушателю полноту ощущения.

Но трудности русского произношения - не главное для создания убедительного художественного прочтения произведения, прочно вошедшего в мировой классический фонд и сохраняющего в то же время статус жемчужины русской культуры. Опера изначально является культурной формой, испытавшей большое влияние межкультурного взаимодействия. Русская оперная школа также сложилась в результате комбинирования «своих» и «чужих» элементов, а при перенесении в инокультурную среду комплексность ее му- 
зыкально-вербально-образной структуры только усиливается. Э. В. Саид, выдающийся исследователь культуры, основоположник и классик постколониальных исследований, подчеркивает, что «вся оперная форма... представляет собой гибрид, радикально неоднородное произведение, которое в равной степени принадлежит и истории культуры, и историческому опыту заморского государства» (Саид, 2012: 247). Данное замечание относится к анализу Саидом оперы Верди «Аида», но оно в полной мере применимо и к постановкам русской оперы на Западе, поскольку Россия в культурном восприятии Запада стоит недалеко от статуса «заморского государства».

Другая трудность в постановках такого рода - найти в растиражированном тексте, давно разобранном на цитаты, поставленном самыми разными русскими и зарубежными оперными театрами, известного английскому зрителю по фильму, о котором мы писали выше, оригинальное решение там, где существует огромное множество вариантов, показать Другого как привлекательного и интересного. Режиссер данной версии «Евгения Онегина» К. Холтен, который дебютировал в Ковент-Гардене этим спектаклем, был заинтересован, прежде всего, историей утраченного прошлого, любви, которая осталась в молодости, лиризмом воспоминания. Отсюда его необычное дублирование Онегина и Татьяны в исполнении С. Кинлисайда и К. Стояновой балетной парой, которая в танце показывает историю несостоявшейся любви в молодости героев. Идеи режиссера, совпадают с тем, что высказала по этому поводу Марта Файнз: «...великие истории пересекают границы времени. Перемены приходят со временем - социальные различия, политика, технология. <..> Но есть вещи, которые остаются - смерть, наше отношение к смерти - они не изменились. И, что невероятно, не изменилась природа любви, природа отвержения или неадекватности или чувства недостойности. Эти базовые вещи и истории любви обычно работают очень хорошо, а эта в особенности» (Meyer et al., 2000: Электронный ресурс; пер. наш. - Е. Ш.). Именно универсальность этой истории во времени и пространстве и интересует режиссера, и, поскольку любовь рассматривается как общечеловеческий феномен, ее конкретный контекст «другости», «русскости» не столь важен, сколько вечное звучание любовной тоски и несбывшихся надежд.

Что касается состава, в нем была только одна русская исполнительница - Ольга, партию которой пела Е. Максимова. Международный состав - еще один показатель преодоления «другости» в интерпретациях русской классики на современной сцене, поскольку еще не так давно русский оперный репертуар был не слишком востребован в мире, а для исполнения приглашались в основном русские артисты, служа признаком аутентичности. Сегодня современная оперная сцена поистине является примером поликультурного пространства, а исполнителям приходится осваивать не только языки оригинала, 
но и различные культурные коды. В случае с «Онегиным» единственным стереотипом «русскости» были, пожалуй, снопы соломы, разбросанные в качестве ностальгического воспоминания в комнате Татьяны в финальной сцене. Главным как для режиссера, так и для исполнителей стала история потерянной любви юности, которая может случиться и часто случается с каждым. Режиссера К. Холтена привлекает не контекст истории, рассказанной Пушкиным и переложенной на язык музыки Чайковским, или культурные реалии России XIX века, а внутренний мир героев и его отражение в музыке. Свой прием соотнесения Онегина и Татьяны, которые показаны людьми вполне зрелого возраста, с их молодыми двойниками он объясняет стремлением выразить ностальгический лиризм Пушкина и Чайковского. Отсюда постепенное появление символов прошлого героев в финальной сцене — комната заполняется книгами, которые составляли жизненную среду молодой Татьяны, снопами соломы - символами деревенской жизни, близкой к природе и, в данном случае, отсылкой к «русскости». Но главным для него является то, что мы видим историю истинной любви, не юношеского увлечения, а чувства, которые герои проносят через всю жизнь.

Несомненно, одним из самых важных моментов в постановке является интерпретация образов главных героев, в данном случае, Онегина и Татьяны, причем в случае с оперным Онегиным понимание и воплощение героя более сложно, чем «прозрачный» и лиричный образ Татьяны, «русской душою», но воспитанной на французских романах и мечтающей о любви, как любая девушка ее возраста. Онегин - персонаж более сложный, воплощающий все черты экзистенциального Другого. Для инокультурного исполнителя важно понять его сущностную «другость», являющуюся, возможно, сердцевиной его характера. С. Кинлисайд говорит о сложности характера молодого Онегина, в котором сочетаются цинизм, очарование, чувство юмора и «который, к сожалению, не понял главного в жизни». Эта трактовка образа героя близка к кинематографической интерпретации Р. Файнза, который рассуждает о важности истории Онегина для сегодняшнего дня: «Она об упущенных возможностях, поскольку человек слишком занят собой, и о том, как можно защитить себя от эмоциональной вовлеченности, от эмоциональной открытости, которая дана Татьяне и не дана Онегину. Он сформировал себя... как интригующий, но холодный... образ. Но он не глуп. Он человек тонкого восприятия, но он проигрывает, поскольку он не осмелился быть ранимым. И я думаю, настоящая эмоциональная честность... более трудна для многих мужчин, чем для женщин» (ibid).

Совпадение трактовки образа героя в фильме и опере не случайно, оно показывает тенденцию европейских «культурных производителей» искать в литературном или музыкальном тексте общечеловеческие проблемы, воз- 
можности их разрешения или ухода от них, находить новые взгляды на такие аспекты человеческого бытия, не исчезнувшие даже в «посткультуре», как любовь, память, верность, и на весь спектр межличностных отношений. Если «другость» и присутствует в этих интерпретациях, то это не этнокультурная, а экзистенциальная «другость» не интегрированного в общество героя, в то время как этнокультурный момент «русскости» (кроме языковой составляющей) присутствует лишь в виде символов и намеков. На наш взгляд, это симптоматично для современного взгляда на классическое наследие, которое притягательно не своей экзотической «другостью», принадлежащей сегодня массовой культуре и туриндустрии, а великими общечеловеческими ценностями, заключенными в ней и ждущими талантливого и бережного интерпретатора в любой форме художественной культуры.

\section{ЗАКЛЮЧЕНИЕ}

Описанные нами примеры симптоматичны для культуры наших дней, когда даже самый наивный потребитель понимает сконструированность расхожих стереотипов о различных культурах: «...демистификация всех культурных конструктов, как “наших", так и “их” — новый факт, который осваивают ученые, критики и художники» (Саид, 2012: 605).

В плюралистическом мире бесчисленных «других» сознание некоего нового пространства сосуществования различных культурных форм возникает иллюзия потеря «другости» как отличительного признака того или иного этнокультурного сообщества, утеря аутентичности в пользу преобладания общечеловеческих элементов в репрезентации разнородных культурных текстов и форм.

В предпринятом нами анализе двух очень качественных и серьезных репрезентаций текста, принадлежащего изначально русской культуре, утверждается универсализм этого текста, основанного на вечных образах. Тем не менее, точку в нашем исследовании ставить еще рано, поскольку любая универсалия нуждается в реификации в культурной практике и детализации в рефлексии. Взгляд Другого на русскую культуру заставляет задуматься об общем и специфичном элементе в ее текстах, о контекстуальной обусловленности репрезентации и разнице в восприятии культурного феномена как «своего» и как «другого».

В контексте интенсивных поисков определения собственной идентичности, ведущихся в области как теории, так и различных социокультурных практик, посмотреть на Себя-как-на-Другого представляется очень важным моментом в самоидентификации. Мы осознаем, что концептуализация «Мыидентичности» для такого сложного поликультурного пространства как современная Россия очень трудна, практически невозможна на всем социокуль- 
турном пространстве нашей страны. Тем не менее, отдельные пространства воплощения в культурные формы и практики взаимоотношения «Я / Другой» могут помочь в прояснении общей картины взаимоотношений многочисленных «Мы» и «Они» (пост)современного мира, и именно с этой целью мы предприняли наш анализ конкретных примеров такого отношения.

\section{СПИСОК ЛИТЕРАТУРЫ}

Густякова, Д. Ю. (2015) Текст русской классической оперы в глобальном контексте массовой культуры // Коды массовой культуры: российский дискурс : коллективная монография / под науч. ред. Т. С. Злотниковой, Т. И. Ерохиной. Ярославль : РИО ЯГПУ. 240 с. С. 137-148.

Кудрявцев, С. (2006) «ОНЕГИН» (Onegin), Великобритания - США. 1998. 105 минут. Режиссер Марта Файнз (Martha Fiennes) : Мелодрамаэкранизация [Электронный ресурс] // kinanet - Живой журнал. 3 октября. URL: https://kinanet.livejournal.com/102079.html [архивировано в WaybackMachine] (дата обращения: 28.03.2019).

Луков, В. А., Луков, Вл. А. (2008) Тезаурусы: Субъектная организация гуманитарного знания. М. : Изд-во Нац. ин-та бизнеса. 784 с.

Мельниченко, Е. (2013) «Евгений Онегин» в «Ковент-Гарден»: как русскую оперу ставят и исполняют иностранцы [Электронный ресурс] // 2queens: информационно-развлекательный портал. 27 февраля URL: http://2queens.ru/Articles/Teatr-Opera/Evgenij-Onegin-v-KoventGarden-kak-russkuyu-operu-stavyat-i-ispolnyayut-inostrancy.aspx?ID=910 [архивировано в WaybackMachine] (дата обращения: 28.03.2019).

Набоков, В. В. (1998) Комментарий к роману А. С. Пушкина «Евгений Онегин» / пер. с англ. СПб. : Искусство-СПБ ; Набоковский фонд. 928 с.

Саид, Э. В (2012) Культура и империализм. СПб. : Владимир Даль. 733, [1] c.

Adorno, T. (1990) Cultural industry reconsidered // Culture and society: Contemporary debates / ed. by J. C. Alexander, S. Seidman. N. Y. : Cambridge University Press. vii, 375 p. P. 275-282.

Jameson, F. (1995) Postmodernism, or, The cultural logic of late capitalism. L. : Verso. xxii, 438 p.

Meyer, A. et al. (2000) Interview: Ralph and Martha Fiennes Push(kin) 19th Century “Onegin” / A. Meyer, R. Fiennes, M. Fiennes [Электронный ресурс] // IndieWire. January 5. URL: https://www.indiewire.com/2000/01/interview-ralphand-martha-fiennes-pushkin-19th-century-onegin-81893/ [архивировано в WaybackMachine] (дата обращения: 28.03.2019).

Operatraveller. (2013) Regrets [Электронный pecypc] // Operatraveller. Operatic wanderer | Flâneur lyrique. February 5. URL: 
https://operatraveller.com/2013/02/05/regrets/ [архивировано в WaybackMachine] (дата обращения: 28.03.2019).

Дата поступления: 29.03.2019 г.

\section{REFERENCES}

Gustiakova, D. Yu. (2015) Tekst russkoi klassicheskoi opery v global'nom kontekste massovoi kul'tury [Text of Russian classical opera in the global context of mass culture]. In: Kody massovoi kul'tury: rossiiskii diskurs [Codes of mass culture: Russian discourse] : A multi-authored monograph / ed. by T. S. Zlotnikova and T. I. Erokhina. Yaroslavl : RIO IaGPU Publ. [Editorial and Publishing Unit at Yaroslavl State Pedagogical University]. 240 p. Pp. 137-148. (In Russ.).

Kudriavtsev, S. (2006) «ONEGIN» (Onegin), Velikobritaniia — SShA. 1998. 105 minut. Rezhisser Marta Fainz (Martha Fiennes) : Melodramaekranizatsiia ["Onegin", Great Britain — USA. 1998. 105 mins. Director Martha Fiennes : Melodrama-cinematization]. kinanet - Zhivoi zhurnal, October 3. [online] Available at: https://kinanet.livejournal.com/102079.html [archived in WaybackMachine] (accessed 28.03.2019). (In Russ.).

Lukov, V. A. and Lukov, Vl. A. (2008) Tezaurusy: Sub"ektnaia organizatsiia gumanitarnogo znaniia [Thesauri: The subjective organization of humanities knowledge]. Moscow : The National Institute of Business Publ. 784 p. (In Russ.).

Melnichenko, E. (2013) «Evgenii Onegin» v «Kovent-Garden»: kak russkuiu operu staviat i ispolniaiut inostrantsy ["Eugene Onegin" in Covent Garden: The way foreigners stage and perform Russian opera]. 2queens: informatsionnorazvlekatel'nyi portal, February 27. [online] Available at: http://2queens.ru/Articles/Teatr-Opera/Evgenij-Onegin-v-KoventGarden-kak-russkuyu-operu-stavyat-i-ispolnyayut-inostrancy.aspx?ID=910 [archived in WaybackMachine] (accessed 28.03.2019). (In Russ.).

Nabokov, V. V. (1998) Kommentarii k romanu A. S. Pushkina «Evgenii Onegin» [Commentary on A.S. Pushkin's novel "Eugene Onegin] / transl. from English. St. Petersburg : Iskusstvo-SPB Publ. ; Nabokovskii fond [Nabokov Foundation]. 928 p. (In Russ.).

Said, E. W (2012) Kul'tura i imperialism [Culture and imperialism]. St. Petersburg : Vladimir Dal'. 733, [1] p. (In Russ.).

Adorno, T. (1990) Cultural industry reconsidered. In: Culture and society: Contemporary debates / ed. by J. C. Alexander and S. Seidman. New York : Cambridge University Press. vii, 375 p. Pp. 275-282.

Jameson, F. (1995) Postmodernism, or, The cultural logic of late capitalism. London : Verso. xxii, $438 \mathrm{p}$. 
Meyer, A. et al. (2000) Interview: Ralph and Martha Fiennes Push(kin) 19th Century "Onegin" / A. Meyer, R. Fiennes, M. Fiennes. IndieWire, January 5. [online] Available at: https://www.indiewire.com/2000/01/interview-ralph-andmartha-fiennes-pushkin-19th-century-onegin-81893/ [archived in WaybackMachine] (accessed 28.03.2019).

Operatraveller. (2013) Regrets. Operatraveller, February 5. [online] Available at: https://operatraveller.com/2013/02/05/regrets/ [archived in WaybackMachine] (accessed 28.03.2019).

Submission date: 29.03.2019.

Шапинская Екатерина Николаевна - доктор философских наук, профессор, профессор кафедры рекламы, связей с общественностью и социально-гуманитарных проблем Российского государственного университета физической культуры, спорта, молодежи и туризма. Адрес: г. Москва, Сиреневый бульвар, д. 4. Тел.: +7 (495) 961-31-11. Эл. адрес: reenash@mail.ru

Shapinskaya Ekaterina Nikolaevna, Doctor of Philosophy, Professor, Department of Advertising, Public Relations and Humanitarian Problems, Russian State University of Physical Education, Sport, Youth and Tourism. Postal address: 4 Sirenevyi Blvd., 105122 Moscow, Russian Federation. Tel.: +7 (495) 961-31-11. E-mail: reenash@mail.ru

Для циитирования:

Шапинская E. H. Репрезентация русской классики в западном мире: британская интерпретация «Евгения Онегина» [Электронный ресурс] // Горизонты гуманитарного знания. 2019. № 2. C. 45-60. URL: http:// journals.mosgu.ru/ggz/article/view/1003 (дата обращения: дд.мм.гггг). DOI: $\underline{10.17805 / \text { ggz.2019.2.3 }}$ 